\title{
Stress-strain hysteresis and strain hardening during cyclic tensile test of Mg-0.6at\% Y alloy
}

\author{
Qinghuan Huo *, Daisuke Ando, Yuji Sutou, Junichi Koike \\ Department of Materials Science, Tohoku University \\ 6-6-11 Aoba, Aramaki, Aoba-ku, Sendai 980-8579, Japan \\ Corresponding author: Tel: +81-022-795-7339, fax: +81-022-795-7338 \\ E-mail: huo.qinghuan.t7@dc.tohoku.ac.jp (Q. Huo)
}

\begin{abstract}
The Mg-0.6at\% Y alloy having an average grain size of $180 \mu \mathrm{m}$ and random texture was subjected to cyclic tensile tests at room temperature. Tensile tests were performed at a strain rate of $1 \times 10^{-3} \mathrm{~s}^{-1}$ for 10 cycles with the peak stress of 40,70 , and $100 \mathrm{MPa}$ with reference to the $0.2 \%$ proof stress of $68 \mathrm{MPa}$. Hysteresis loops and cyclic strain hardening were observed in all peak stress cases. The observation of slip traces and twin types suggested that the hysteresis behavior was due to synchronous movement of basal slip and anomalous $\{10 \overline{1} 2\}$ twinning, and that the cyclic strain hardening was due to non-basal slip. Prismatic slip led to cyclic strain hardening when peak stress was below the proof stress, and both prismatic and pyramidal slip promoted larger cyclic strain hardening when peak stress was increased over the proof stress.
\end{abstract}

Keywords: magnesium; twinning; dislocation; strain hardening. 


\section{Introduction}

Recently, magnesium (Mg) alloys have attracted great interest and become one of the most important light-weight structural materials in many industries [1-3]. As structural materials in service, $\mathrm{Mg}$ alloys are usually subjected to repeated loading and unloading cycles, and the deformation behavior and mechanism need to be clearly understood. Since Mg alloys have hexagonal close-packed (hcp) structure, cyclic deformation mechanism tends to differ from those in cubic metals [4-6]. As is known, $\{10 \overline{1} 2\}$ twinning and basal slip are the dominant deformation mechanisms of $\mathrm{Mg}$ alloys at room temperature. The activation of $\{10 \overline{1} 2\}$ twinning is significantly affected by initial orientation [7-10], and detwinning always takes place during unloading [11-15]. So $\{10 \overline{1} 2\}$ twinning-detwinning is considered to be a crucial mechanism in fatigue tests of $\mathrm{Mg}$ alloys.

Fatigue tests can be performed either in a strain-controlled mode or in a stress-controlled mode. Depending on the test mode, dominant mechanisms may be different $[12,16]$. For strain-controlled fatigue, $\{10 \overline{1} 2\}$ twinning-detwinning is regarded as a primary mechanism [17-27]. Similarly, for stress-controlled fatigue, twinning-detwinning is considered to be a main fatigue mechanism in the initial cycles. While in the late cycles, non-basal dislocation slip is considered to dominate $[15,16,28]$. In our previous paper on textured $\mathrm{AZ31} \mathrm{Mg}$ alloy, stress-controlled fatigue mechanisms were studied in detail by performing cyclic tensile tests [29]. It was found that $\{10 \overline{1} 2\}$ twinning-detwinning occurred both below and above yield stress, whereas prismatic slip only occurred when the peak stress was above the yield stress. In addition, $\{10 \overline{1} 1\}-\{10 \overline{1} 2\}$ double twins were observed under large surface steps, and their accumulation gave rise to serious strain incompatibility leading to final fracture.

From the aforementioned findings, note that fatigue mechanisms are always related to $\{10 \overline{1} 2\}$ twinning-detwinning. It has been well-known that $\{10 \overline{1} 2\}$ twinning in $\mathrm{Mg}$ 
alloy is strongly influenced by the relative crystallographic orientation of matrix grains to the external loading direction $[30,31]$. Twinning tendency also depends on alloying element [32-36]. Therefore, alloying elements and initial orientation distribution (crystallographic texture) are expected to affect fatigue processes.

In terms of the texture, wrought $\mathrm{Mg}$ alloys in general have serious plastic anisotropy because of strong basal texture. However, rare-earth element (RE) addition can change various deformation characteristics of $\mathrm{Mg}$ alloys. For example, non-basal slip systems are easily activated while $\{10 \overline{1} 2\}$ twinning may be prohibited to some extent [32-36]. These features of Mg-RE alloys bring weak crystallographic texture and improved ductility at room temperature [36-38]. However, up to now, few reports have been reported for fatigue mechanisms in Mg-RE alloys. The specific fatigue mechanisms of $\mathrm{Mg}-\mathrm{RE}$ alloys remain unclear.

In this paper, stress-controlled cyclic tensile tests were performed and corresponding deformation mechanisms were investigated on $\mathrm{Mg}-0.6 \mathrm{at} \% \mathrm{Y}$ alloy. Among various $\mathrm{Mg}-\mathrm{RE}$ alloys, $\mathrm{Mg}-\mathrm{Y}$ alloys have been investigated most extensively and a good number of fundamental data are available. It is hoped that the results in the present work can enrich the understanding of $\mathrm{Mg}-\mathrm{RE}$ alloy fatigue mechanisms and expedite the application of Mg-RE alloys.

\section{Experimental procedure}

Samples used in this study were hot-extruded sheets of $\mathrm{Mg}-0.6$ at\% Y alloy. Dog-bone shaped samples were prepared by cutting the extruded sheet with an electro discharge machine. The dimension of gauge area was $10 \mathrm{~mm}$ in length (parallel to the extrusion direction, ED), $3.6 \mathrm{~mm}$ in width (parallel to the transverse direction, TD), and $1.8 \mathrm{~mm}$ in thickness (parallel to the normal direction, ND). Since twinning could easily take place in large grains during deformation, homogenization treatment was performed at $723 \mathrm{~K}$ for $8 \mathrm{~h}$, followed by water quenching so as to eliminate pre-existing twins before cyclic tensile test. The obtained samples had equi-axed grains with an average grain size of $180 \mu \mathrm{m}$ (Fig. 1(a)). No precipitate was found in 
grain interior or along grain boundaries. Initial texture was found to be random, as Fig. 1(b) showing uniformly distributed intensity for the poles of various planes.

In order to identify dominant deformation mechanisms from slip traces, a mirror finished surface was prepared by the following method. The surfaces of the samples were mechanically ground with \#1200, \#2400, and \#4000 abrasive papers, followed by polishing with 1 and $0.25 \mu \mathrm{m}$ diamond pastes. Finally, chemical polishing was carried out using a solution of nitric acid $(10 \mathrm{ml})$ and absolute ethanol (100 ml). These samples were subjected to cyclic tensile test at room temperature at a strain rate of $1 \times$ $10^{-3} \mathrm{~s}^{-1}$ for 10 cycles by continuously changing applied stress between zero and peak stress, $\sigma_{\max }$. Uniaxial tensile test was carried out in separate samples at the same temperature and strain rate with cyclic tensile test. The $0.2 \%$ proof stress and ultimate tensile stress were found to be 68 and $140 \mathrm{MPa}$, respectively. With reference to these values, the peak stress values, $\sigma_{\max }$, for cyclic tensile test, were selected to be 40,70 , and $100 \mathrm{MPa}$.

Stress-strain curves obtained by cyclic tensile test were analyzed by extracting characteristic parameters shown in Fig. 2. This figure shows the schematic illustration of stress-strain curves of one segment of cyclic tensile test. Suppose that a sample is loaded to $\sigma_{\max }$, unloaded to zero, and reloaded to $\sigma_{\max }$. During the unloading-reloading cycle, a hysteresis loop would be observed. By this figure, several relevant parameters used in this work are now defined, following the method proposed in Ref. [39-42]. Here, $E$ is the intrinsic Young's modulus of $\mathrm{Mg}$ (42 GPa). $E_{\mathrm{s}}$ is secant Young's modulus which is obtained by drawing a straight line between the top and bottom of the hysteresis loop. Plastic strain, $\varepsilon_{\mathrm{p}}$, is defined as the strain at the bottom of the loop. Anelastic strain, $\varepsilon_{\mathrm{a}}$, is defined as strain between the loop bottom and the intersecting point of the straight line drawn from the loop top with a slope of $E$ to the horizontal axis. The rest is elastic strain, $\varepsilon_{\mathrm{e}}$.

After cyclic tensile tests, the gauge areas were cut to observe the microstructure with an optical microscope (OM) and a scanning electron microscope (SEM), and the crystallographic orientation distribution with an electron backscatter diffraction (EBSD) apparatus. 


\section{Results}

Fig. 3 shows the engineering stress-strain curves of $\mathrm{Mg}-\mathrm{Y}$ alloy during cyclic tensile test for 10 cycles with $\sigma_{\max }=40,70$, and $100 \mathrm{MPa}$. Hysteresis loops are observed in all cases. The shift of the loop bottom position indicates the increase of plastic strain with increasing the cycle number. It is noted that the magnitude of the shift decreases after three or four cycles. This is due to strain hardening after each cycle of tensile test. The strain hardening tendency becomes more obvious with increasing $\sigma_{\max }$. Compared to our previous work on AZ31 alloy with nearly the same average grain size [29], here, strain hardening in $\mathrm{Mg}-\mathrm{Y}$ alloy is more serious. No strain hardening occurs at $\sigma_{\max }=40 \mathrm{MPa}$ of AZ31 alloy while strain hardening at $\sigma_{\max }$ $=40 \mathrm{MPa}$ of $\mathrm{Mg}-\mathrm{Y}$ is much larger than that at $\sigma_{\max }=100 \mathrm{MPa}$ of AZ31 alloy.

Fig. 4(a) shows the relationship between $\varepsilon_{\mathrm{p}}$ and the cycle number $N$. As explained already in Fig. $3, \varepsilon_{\mathrm{p}}$ increases gradually with increasing $N$. At $\sigma_{\max }=100 \mathrm{MPa}, \varepsilon_{\mathrm{p}}$ is much greater than at $\sigma_{\max }=40$ and $70 \mathrm{MPa}$. Fig. 4(b) shows that $\varepsilon_{\mathrm{a}}$ decreases gradually up to the fourth cycle at $\sigma_{\max }=70$ and $100 \mathrm{MPa}$. After the fourth cycle, $\varepsilon_{\mathrm{a}}$ tends to become steady. This implies that the effect of twinning becomes weak after the fourth cycle. At $\sigma_{\max }=40 \mathrm{MPa}, \varepsilon_{\mathrm{a}}$ remains unchanged during the whole 10 cycles, suggesting that detwinning is fully completed. To understand the strain hardening behavior quantitatively, the following relation is considered for plastic strain increment, $\Delta \varepsilon_{\mathrm{p}}$, and the logarithmic of $N[29,43]$ :

$\Delta \varepsilon_{\mathrm{p}}=-\beta \cdot \log N+C$

here, $\beta$ and $C$ are constants. $\beta$ is a measure of strain hardening and $C$ corresponds to the plastic strain after the first cycle. The relationship between $\Delta \varepsilon_{\mathrm{p}}$ and $\log N$ is plotted in Fig. 4(c). With increasing $\log N, \Delta \varepsilon_{\mathrm{p}}$ decreases faster at $\sigma_{\max }=100 \mathrm{MPa}$ than at $\sigma_{\max }=40$ and $70 \mathrm{MPa}$. Fig. 4(d) shows the relationship between $\beta$ and $\sigma_{\max }$. As expected, the $\beta$ value increases with increasing $\sigma_{\max }$.

For comparison, $\beta$ of AZ31 Mg alloy from our previous work [29] is plotted in the same figure. The $0.2 \%$ proof stress and ultimate tensile stress of AZ31 were 85 and $189 \mathrm{MPa}$, respectively. Grain size was $220 \mu \mathrm{m}$. It is found that $\beta$ of AZ31 is much 
smaller at 40 and $70 \mathrm{MPa}$ than that of Mg-Y, but becomes a similar large value at 100 $\mathrm{MPa}$ to that of Mg-Y. It is suggested that strain hardening is surprisingly significant in $\mathrm{Mg}-\mathrm{Y}$ alloy even if $\sigma_{\max }$ is below the yield stress. This result in Fig. 4(d) implies that the fatigue limit of $\mathrm{Mg}-\mathrm{Y}$ alloy may decrease to a level below its yield stress. Therefore, it is deemed important to research the relationship between this fast strain hardening and the fatigue limit in Mg-Y alloy. This work will be reported in a separate paper.

Fig. 5 shows typical SEM images after cyclic tensile test at different stress amplitudes. Characteristic regions are circled by red dotted lines. As shown in Fig. 5(a), at $\sigma_{\max }=40 \mathrm{MPa}$, in addition to fine slip lines due to basal dislocations, Grain A shows sharp slip lines near a grain boundary and cross each other at an angle of nearly $60^{\circ}$. They are considered to be the slip traces of prismatic dislocations. By increasing $\sigma_{\max }$ to $70 \mathrm{MPa}$ (Fig. 5(b)), similar slip lines are observed in Grain B, which is probably due to prismatic dislocations. Note that the prismatic dislocation traces should be nearly straight as observed here. This is because the Burgers vector of the prismatic dislocation is $\boldsymbol{a}$, and cross slip cannot occur from one prismatic plane to another. Alternatively, cross slip can occur from basal to prismatic planes when their Burgers vectors are of the same $\boldsymbol{a}$ type [44]. In Grain C, wavy slip lines with thin steps are observed. Generally, wavy lines are due to cross slip of dislocations. Note that the appearance of the wavy dislocations in Grain $\mathrm{C}$ is different from that of the basal slip in Grain A at $40 \mathrm{MPa}$ or from that of the prismatic slip in Grain B at $70 \mathrm{MPa}$. Thus the wavy lines are considered to be due to pyramidal dislocations. In Grains D and E, short and heavy wavy lines can be observed. These lines are also cross slip as pyramidal dislocations are likely to glide from one pyramidal plane to its adjacent pyramidal plane. By increasing $\sigma_{\max }$ to $100 \mathrm{MPa}$ (Fig. 5(c)), a $60^{\circ}$ interactive slip couple is observed in Grain F. Wavy slip lines with obvious surface step are observed more clearly and larger in number in Grains $\mathrm{G}$ and $\mathrm{H}$.

Fig. 6 shows typical OIM maps of Mg-Y alloy after cyclic tensile test for 10 cycles. Since the projection axis is parallel to ND, blue and green grains denote grains with their $c$-axis perpendicular to ND, and red grains have their $c$-axis parallel to ND. All 
twins are detected to be $\{10 \overline{1} 2\}$ type in Fig. 6. At $\sigma_{\max }=40 \mathrm{MPa}$, grains have no obvious orientation gradient and no twins. At $\sigma_{\max }=70 \mathrm{MPa}$, some twins are observed within grains, which are the so-called "residual twins" [24-26, 45]. At $\sigma_{\max }=$ $100 \mathrm{MPa}$, more residual twins are observed. Color variation within a grain is detected insides some grains (indicated by black arrows in Fig. 6(c)), which is caused by internal orientation gradient. The orientation gradient indicates the accumulation of significant strain.

Additionally, the type of residual $\{10 \overline{1} 2\}$ twins can be classified as either "normal" or "anomalous" twins, based on relative orientation relation between the twins' $<\mathrm{c}>$ axis direction and the external stress direction [46]. It is known from geometrical consideration that the normal $\{10 \overline{1} 2\}$ twins are formed under tension in the $\langle c\rangle$ axis and under compression in the $<\mathrm{a}>$ axis [9-12]. On the other hand, the "anomalous" $\{10 \overline{1} 2\}$ twins are formed in geometrically impossible conditions under compression in the $\langle\mathrm{c}>$ axis and tension in the $<\mathrm{a}>$ axis, or under external stress acting upon grains with their $\langle c\rangle$ axis having large angle from loading direction. In Fig. 6, normal residual twins are seen in red, whereas anomalous residual twins are seen in other colors than red. Fig. 7 shows how to distinguish between normal and anomalous twins in representative grains surrounded by white dotted lines in Figs. 6(b) and (c). In stereographic projections of Fig. $7,\{0001\}$ poles of matrices and twins are indicated with black solid and blue open symbols, respectively. The tensile direction is along ED. Figs. 7(a) and (c) show the case of normal twins which accompany the rotation of $\{0001\}$ pole from ED and its adjacent to ND. Note that the matrix $\{0001\}$ poles are nearly parallel to the tension direction, namely, producing tension twins. Figs. 7(b) and (d) show the case of anomalous twins. In this case, the matrix (0001) poles are tilted from ED, indicating the high activity of basal slip. The twin poles are located along the line connecting ND and TD. These analyses of twin type indicate that most of the residual twins observed in Fig. 6 are of the anomalous type that accompanies the high basal slip activity. 


\section{Discussion}

The present work shows hysteresis loops at all three peak stress values in $\mathrm{Mg}-\mathrm{Y}$ alloy. It has been known that the hysteresis loops are due to the thickening and thinning of $\{10 \overline{1} 2\}$ twins, or twinning and detwinning, during loading and unloading $[18,24,33]$. The OIM map in Fig. 6(a) after the 10th cycle indicates no residual twins at $\sigma_{\max }=40 \mathrm{MPa}$. With increasing $\sigma_{\max }$ to 70 and to $100 \mathrm{MPa}$, the number of residual twins increases. The difference in the number of residual twins at different $\sigma_{\max }$ values can be attributed to the activation of non-basal dislocations, as explained in the following.

When stress is small to activate only basal slip and $\{10 \overline{1} 2\}$ twinning, basal slip would occur first and basal dislocations would be piled up at grain boundaries. This would give rise to the build-up of back stress, leading to the formation of anomalous twins. During unloading, back stress drives the reverse movement of basal slip that is accompanied by detwinning. Therefore, basal slip and anomalous twinning occur in a synchronous manner. This is consistent with the observation in Fig. 6 and in Figs. 7(b) and (d), showing the concomitant activity of the basal slip and the anomalous twinning. Also, as shown in Fig. $4(\mathrm{~b})$ at $\sigma_{\max }=40 \mathrm{MPa}, \varepsilon_{\mathrm{a}}$ remains nearly unchanged from the beginning till the final 10th cycles. This is due to the completely reversible activity of basal slip, twinning and detwinning without non-basal slip relieving the back stress. Meanwhile, when external stress becomes large and the amount of non-basal slip is increased in the grain under consideration as well as in its surrounding grains, back stress is partially or entirely relieved by the non-basal slip. Thus, the driving force for the reversal movement of basal slip and detwinning are also expected to diminish. For this reason, as shown in Fig. 4(b) at the large values of $\sigma_{\max }=70$ and $100 \mathrm{MPa}, \varepsilon_{\mathrm{a}}$ decreases with increasing the cycle number where non-basal slip is active.

It may be argued that anomalous twins are not formed during loading, but during unloading as reported in some previous publications [47-49]. However, Jain et al. [50] 
used in-situ neutron diffraction measurements and confirmed that anomalous twins, the same type as in the present work, are indeed formed during tensile loading. Koike et al. [46] performed calculation of strain tensors associated with basal slip, and showed that anomalous twins can be activated to compensate strain incompatibility among grains. Furthermore, at $\sigma_{\max }=70$ and $100 \mathrm{MPa}$ in this work, geometrically feasible twins are fewer than anomalous ones (Fig. 6). Therefore, the hysteresis loops are considered to be mainly caused by anomalous twins upon loading and detwinning during unloading. In consideration of these reasons, the name "anomalous" twins are applied in this work.

The present work also shows a contrasting hardening behavior below the proof stress between Mg-Y and AZ31 alloys. As shown in Fig. 4(d) from our previous work [29], AZ31 alloy having the proof stress of $85 \mathrm{MPa}$ showed negligibly small hardening constant at $\sigma_{\max }=40 \mathrm{MPa}$, and slightly increased at $70 \mathrm{MPa}$. Finally at 100 $\mathrm{MPa}$, hardening constant became a large value that was accompanied with the appearance of prismatic slip traces on the tested sample surface. It had been well known in AZ31 alloys that micro-yielding occurs by basal slip and twinning below proof stress, and that macro-yielding occurs by non-basal slip above proof stress [51]. These results had led us to conclude that the cyclic hardening in AZ31 alloy was not caused by basal slip nor by twinning-detwinning but by prismatic slip that became active above the proof stress [29].

In contrast, $\mathrm{Mg}-\mathrm{Y}$ alloy shows notable cyclic strain hardening at $\sigma_{\max }=40 \mathrm{MPa}$ below its proof stress of $68 \mathrm{MPa}$. With increasing $\sigma_{\max }$ to $70 \mathrm{MPa}$ and to $100 \mathrm{MPa}$, hardening constant increases monotonously. The notable hardening at $40 \mathrm{MPa}$ can be attributed to the irreversible motion of dislocations, most likely of non-basal type. There are some reports suggesting the occurrence of non-basal slip in $\mathrm{Mg}-\mathrm{Y}$ dilute alloys at room temperature [52-54]. Table 1 shows the critical resolved shear stress (CRSS) of possible deformation modes of pure $\mathrm{Mg}, \mathrm{AZ31}$ alloy, and $\mathrm{Mg}-\mathrm{Y}$ alloys with different $\mathrm{Y}$ contents. Here, the CRSS value of $\mathrm{Mg}-0.6$ at $\% \mathrm{Y}$ can be estimated by assuming linear extrapolation of the reported values of $\mathrm{Mg}-0.5 \mathrm{at} \% \mathrm{Y}$ and $\mathrm{Mg}-0.8 \mathrm{at} \% \mathrm{Y}$ 
alloys. It is clearly seen that the CRSS of prismatic slip is much higher than $\{10 \overline{1} 2\}$ twinning in pure Mg and AZ31 alloy. Therefore, AZ31 can exhibit the synchronous activity of basal slip and twinning at low stress, which leads to the hysteresis without notable hardening. At high stress above the proof stress, prismatic slip becomes active and leads to hardening [29]. However, in Mg-Y alloys, the CRSS of prismatic slip is sharply reduced to be nearly equal to or lower than the CRSS of $\{10 \overline{1} 2\}$ twinning. Therefore, it is likely that the prismatic slip occurs at $\sigma_{\max }=40 \mathrm{MPa}$ and contributes to cyclic strain hardening even below the $0.2 \%$ proof stress.

The enhanced activity of non-basal slip has been reported in Mg-Y alloy and was considered to be a major reason for improved room-temperature ductility [33]. Sandlöbes et al. [33, 55] investigated the dislocation type of $\mathrm{Mg}-3 \mathrm{wt} \% \mathrm{Y}$ (Mg-0.84at\% Y) after cold rolling to the thickness reduction of 3\%. Among all dislocations analyzed by TEM, more than $30 \%$ were found to be pyramidal dislocations of screw type [55]. As is seen in Table 1, the CRSS of pyramidal slip is not shown in those references. However, the SEM images after cyclic test at 70 and $100 \mathrm{MPa}$ (Figs. 5(b) and (c)) suggest that pyramidal slip becomes active above the proof stress of $68 \mathrm{MPa}$. The evidence of heavy cross slip in the images also suggests that these pyramidal dislocations are of screw type, in accordance with the TEM observation by Sandlöbes et al $[33,55]$.

\section{Summary}

The Mg-0.6at\% Y alloy, having an average grain size of $180 \mu \mathrm{m}$ and a random texture, was subjected to cyclic tensile test at room temperature. Tensile tests were performed at a strain rate of $1 \times 10^{-3} \mathrm{~s}^{-1}$ for 10 cycles. Peak stress values were selected to be 40,70 , and $100 \mathrm{MPa}$, in reference to the $0.2 \%$ proof stress of $68 \mathrm{MPa}$.

SEM micrographs showed the development of slip traces with increasing the peak stress. From the low stress to high stress, the observed slip traces were fine parallel lines, thick straight lines crossing each other at an angle of approximately $60^{\circ}$, and heavily stepped short lines. These traces were considered to be due to basal slip, 
prismatic slip, and pyramidal slip, respectively. EBSD images also showed that residual twins observed after cyclic tensile test were mostly anomalous $\{10 \overline{1} 2\}$ twins. Hysteresis loops and cyclic strain hardening were seen in all peak stress cases. The hysteresis was due to the synchronous activity of basal slip and anomalous twinning in association with back stress. Cyclic strain hardening was due to the activation of prismatic slip at $40 \mathrm{MPa}$ below the proof stress, and to the activation of both prismatic and pyramidal slip at 70 and $100 \mathrm{MPa}$ above the proof stress.

The cyclic strain hardening below the proof stress of $68 \mathrm{MPa}$ suggested weaker resistance against fatigue failure in comparison to AZ31 alloy in which no notable cyclic hardening was observed below the proof stress of $85 \mathrm{MPa}$.

\section{Acknowledgements}

Q. Huo gratefully acknowledges the financial supports from the National Science Foundation of China (Grant No. 51474241) and the National Construction High-Level University Government-Sponsored Graduate Student Program of Chinese Scholarship Council (CSC). D. Ando acknowledges sample preparation from TOYOTA Corporation.

\section{References}

[1] T. Al-Samman, Mater. Des. 65 (2015) 983-988.

[2] T. Hama, N. Kitamura, H. Takuda, Mater. Sci. Eng. A 583 (2013) 232-241.

[3] M. Horynová, J. Zapletal, P. Doležal, P. Gejdoš, Mater. Des. 45 (2013) 253-264.

[4] Q. Huo, X. Yang, H. Sun, B. Li, J. Qin, J. Wang, J. Ma, J. Alloys Compd. 581 (2013) 230-235.

[5] X, Huang, K. Suzuki, Y. Chino, Mater. Sci. Eng. A 560 (2013) 232-240.

[6] D. Ando, J. Koike, Y. Sutou, Acta Mater. 58 (2010) 4316-4324.

[7] H. Somekawa, T. Mukai, Mater. Lett. 76 (2012) 32-35.

[8] M.R. Barnett, Mater. Sci. Eng. A 464 (2007) 1-7.

[9] Q. Huo, X. Yang, J. Ma, H. Sun, J. Wang, L. Zhang, J. Mater. Sci. 48 (2013) 
913-919.

[10] D.W. Brown, S.R. Agnew, M.A.M. Bourke, T.M. Holden, S.C. Vogel, C.N. Tomé, Mater. Sci. Eng. A 399 (2005) 1-12.

[11] M. Lee, R.H. Wagoner, J.K. Lee, K. Chung, H.Y. Kim, Int. J. Plast. 24 (2008) $545-582$.

[12] S. Hasegawa, Y. Tsuchida, H. Yano, M. Matsui, Int. J. Fatigue 29 (2007) 1839-1845.

[13] S.H. Park, S.G. Hong, B.H. Lee, W. Bang, C.S. Lee, Int. J. Fatigue 32 (2010) $1835-1842$.

[14] M. Huppmann, M. Lentz, K. Brömmelhoff, W. Reimers, Mater. Sci. Eng. A 527 (2010) 5514-5521.

[15] Q. Li, Q. Yu, J. Zhang, Y. Jiang, Scr. Mater. 62 (2010) 778-781.

[16] M. Matsuzuki, S. Horibe, Mater. Sci. Eng. A 504 (2009) 169-174.

[17] D.K. Xu, E.H. Han, Scr. Mater. 69 (2013) 702-705.

[18] S.M. Yin, H.J. Yang, S.X. Li, S.D. Wu, F. Yang, Scr. Mater. 58 (2008) 751-754.

[19] C.L. Fan, D.L. Chen, A.A. Luo, Mater. Sci. Eng. A 519 (2009) 38-45.

[20] J.B. Jordon, J.B. Gibson, M.F. Horstemeyer, H. El Kadiri, J.C. Baird, A.A. Luo, Mater. Sci. Eng. A 528 (2011) 6860-6871.

[21] F. Lv, F. Yang, Q.Q. Duan, T.J. Luo, Y.S. Yang, S.X. Li, Z.F. Zhang, Scr. Mater. 61 (2009) 887-890.

[22] F. Lv, F. Yang, S.X. Li, Z.F. Zhang, Scr. Mater. 65 (2011) 53-56.

[23] G. Huang, J. Li, T. Han, H. Zhang, F. Pan, Mater. Des. 58 (2014) 439-444.

[24] Y.J. Wu, R. Zhu, J.T. Wang, W.Q. Ji, Scr. Mater. 63 (2010) 1077-1080.

[25] S.H. Park, S.G. Hong, C.S. Lee, Scr. Mater. 62 (2010) 666-669.

[26] S. Begum, D.L. Chen, S. Xu, A.A. Luo, Mater. Sci. Eng. A 517 (2009) 334-343.

[27] T. Hanlon, Y.N. Kwon, S. Suresh, Scr. Mater. 49 (2003) 675-680.

[28] H. Wang, P.D. Wu, J. Wang, Comput. Mater. Sci. 96 (2015) 214-218.

[29] J. Koike, N. Fujiyama, D. Ando, Y. Sutou, Scr. Mater. 63 (2010) 747-750.

[30] M.H. Yoo, Metall. Trans. A 12 (1981) 409-418.

[31] B. Wang, L. Deng, C. Adrien, N. Guo, Z. Xu, Q. Li, Mater. Charact. 108 (2015) 
$42-50$.

[32] B.L. Wu, Y.H. Zhao, X.H. Du, Y.D. Zhang, F. Wagner, C. Esling, Mater. Sci. Eng. A 527 (2010) 4334-4340.

[33] S. Sandlöbes, S. Zaefferer, I. Schestakow, S. Yi, R. Gonzalez-Martinez, Acta Mater. 59 (2011) 429-439.

[34] M. Suzuki, T. Kimura, J. Koike, K. Maruyama, Scr. Mater. 48 (2003) 997-1002.

[35] J.M. Rosalie, H. Somekawa, A. Singh, T. Mukai, J. Alloys Compd. 550 (2013) 114-123.

[36] Q. Peng, Y. Huang, K.U. Kainer, N. Hort, Mater. Lett. 83 (2012) 209-212.

[37] X. Huang, K. Suzuki, Y. Chino, Mater. Sci. Eng. A 538 (2012) 281-287.

[38] N. Kumar, D. Choudhuri, R. Banerjee, R.S. Mishra, Int. J. Plast. 68 (2015) 77-97.

[39] C.H. Cáceres, T. Sumitomo, M. Veidt, Acta Mater. 51 (2003) 6211-6218.

[40] G.E. Mann, T. Sumitomo, C.H. Cáceres, J.R. Griffiths, Mater. Sci. Eng. A 456 (2007) 138-146.

[41] J. Min, J. Lin, Mater. Sci. Eng. A 561 (2013) 174-182.

[42] S.Y. Lee, M.A. Gharghouri, Mater. Sci. Eng. A 572 (2013) 98-102.

[43] S. Begum, D.L. Chen, S. Xu, A.A. Luo, Int. J. Fatigue 31 (2009) 726-735.

[44] J. Koike, R. Ohyama, Acta Mater. 53 (2005) 1963-1972.

[45] L. Wu, A. Jain, D.W. Brown, G.M. Stoica, S.R. Agnew, B. Clausen, D.E. Fielden, P.K. Liaw, Acta Mater. 56 (2008) 688-695.

[46] J. Koike, Y. Sato, D. Ando, Mater. Trans. 12 (2008) 2792-2800.

[47] R.E. Reed-Hill, Trans. Metall. Soc. AIME 218 (1960) 554-558.

[48] F.E. Hauser, C.D. Starr, L. Tietz, J.E. Dorn, Trans. ASM 47 (1955) 102-134.

[49] M.R. Barnett, Z. Kechavarz, M.D. Nave, Metall. Mater. Trans. A 36 (2005) 1697-1704.

[50] A. Jain, O. Duygulu, D.W. Brown, C.N. Tomé, S.R. Agnew, Mater. Sci. Eng. A 486 (2008) 545-555.

[51] M.R. Barnett, Z. Keshavarz, A.G. Beer, D. Atwell, Acta Mater. 52 (2004) 5093-5103.

[52] T. Mineta, S. Miura, T. Mukai, M. Ueda, T. Mohri, J. Japan Inst. Met. Mater. 77 
(2013) 466-472.

[53] S. Miura, S. Imagawa, T. Toyoda, K. Ohkubo, T. Mohri, Mater. Trans. 49 (2008) 952-956.

[54] G. Proust, C.N. Tomé, A. Jain, S.R. Agnew, Int. J. Plast. 25 (2009) 861-880.

[55] S. Sandlöbes, M. Friák, J. Neugebauer, D. Raabe, Mater. Sci. Eng. A 576 (2013) 61-68. 
(a)
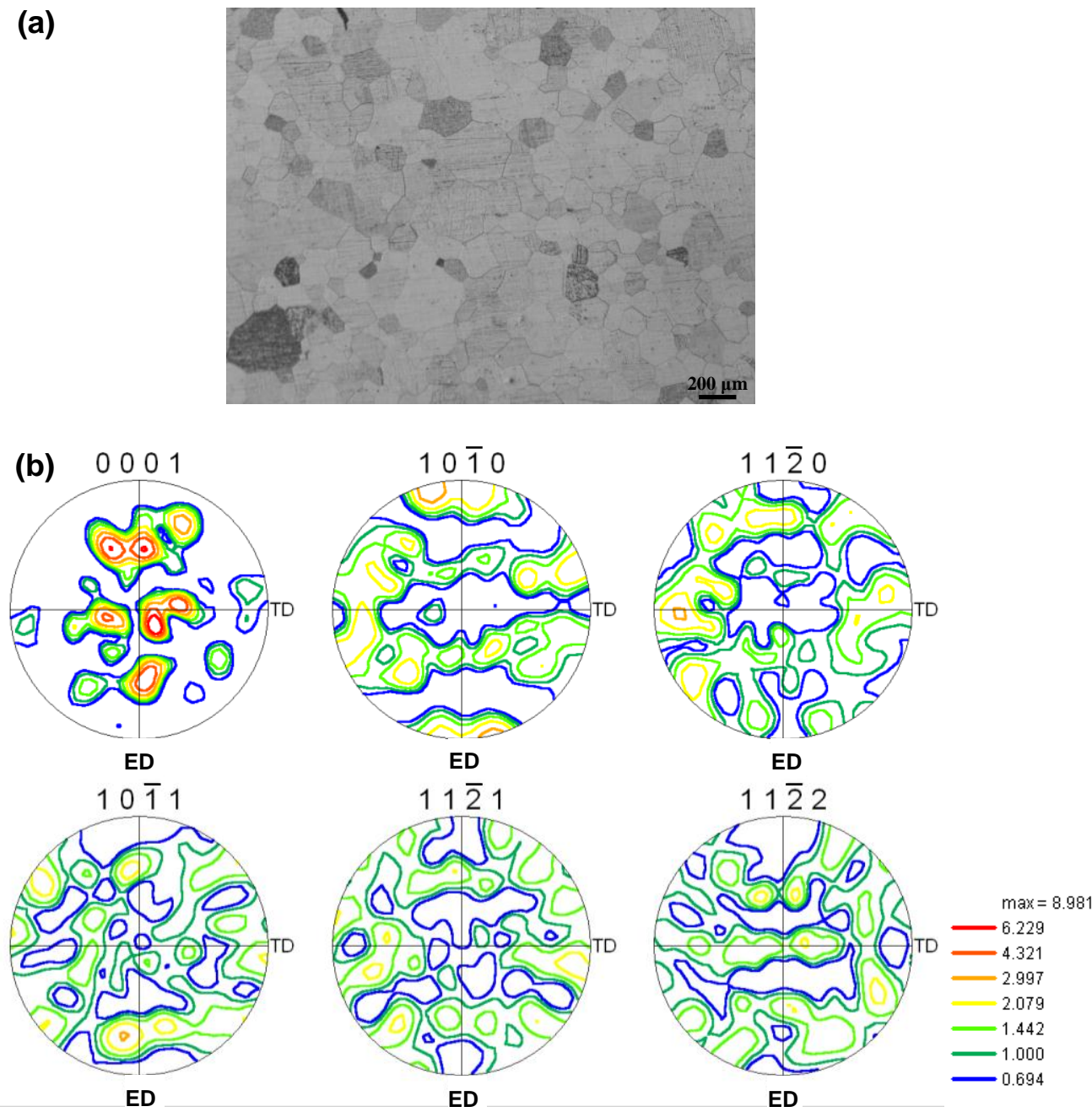

Fig. 1. (a) Microstructure and (b) pole figures of $\mathrm{Mg}-\mathrm{Y}$ alloy after homogenization annealing. 


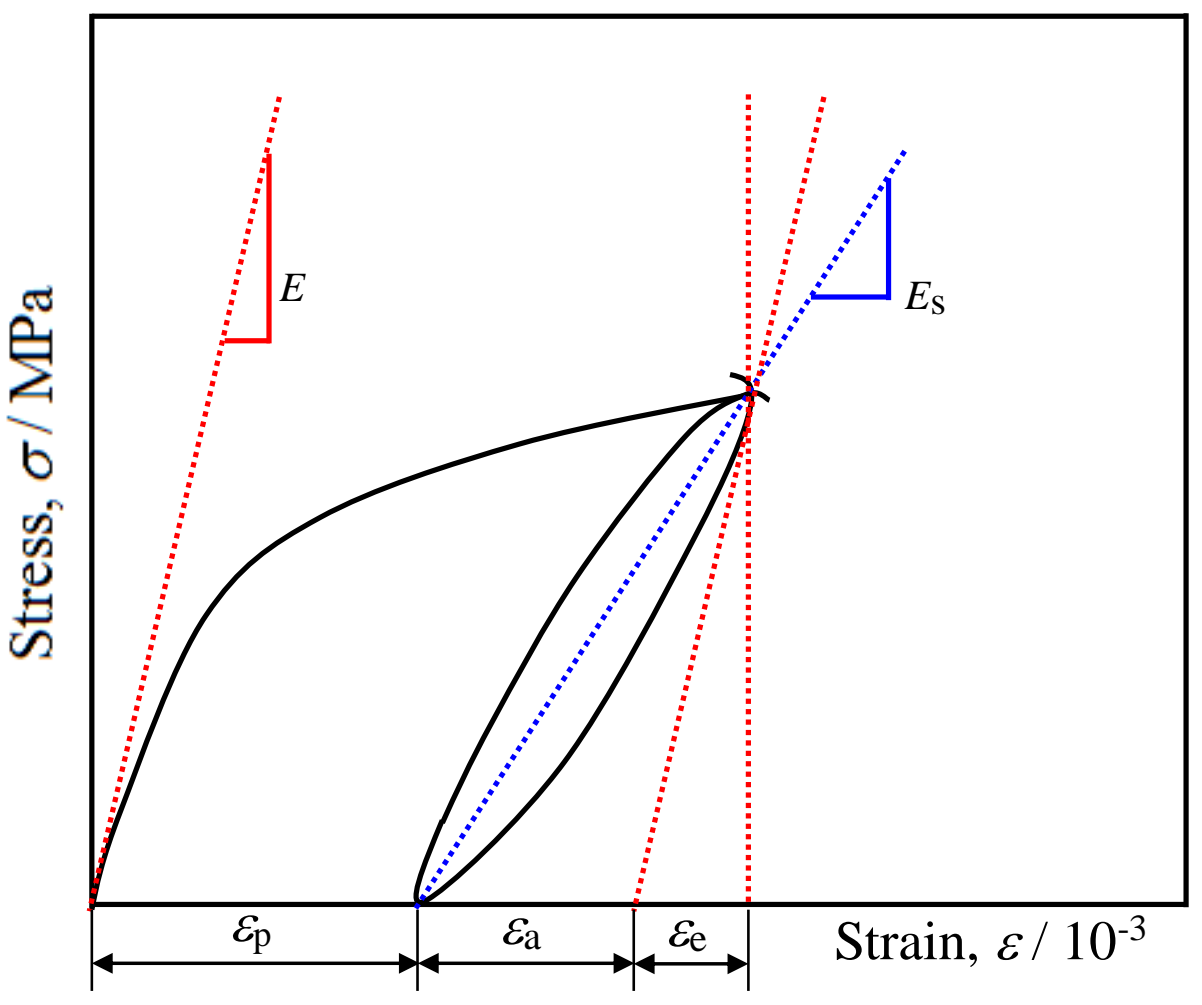

Fig. 2. Schematic illustration of unloading-reloading hysteresis loops. $E$ is intrinsic elastic modulus, $E_{\mathrm{s}}$ is secant modulus, $\sigma$ is engineering stress, $\sigma_{\max }$ is peak stress, $\varepsilon$ is engineering strain, $\varepsilon_{\mathrm{p}}, \varepsilon_{\mathrm{a}}$, and $\varepsilon_{\mathrm{e}}$ are plastic strain, anelastic strain and elastic strain corresponding to unloading to zero, respectively. 

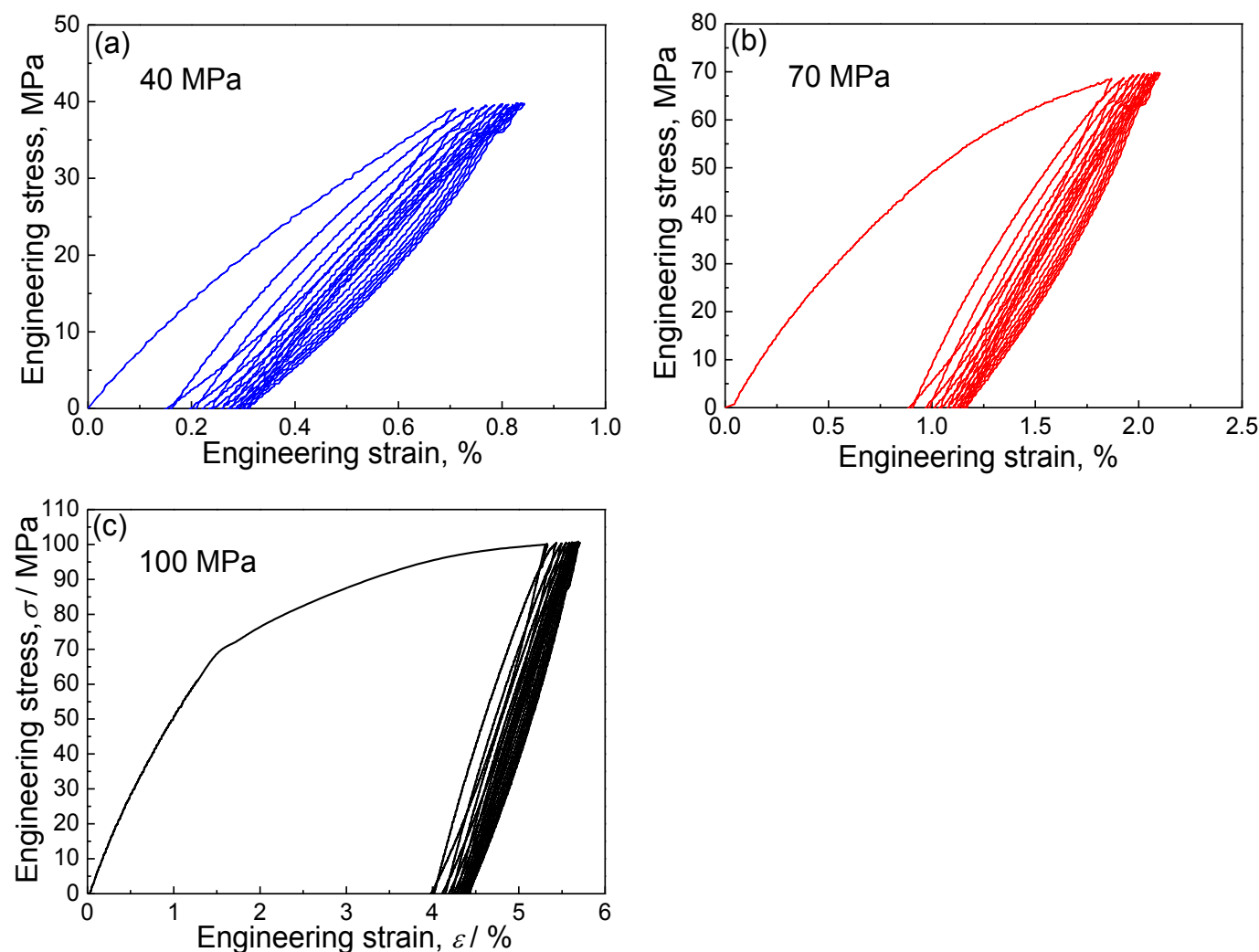

Fig. 3. Engineering stress-strain curves of $\mathrm{Mg}-\mathrm{Y}$ alloy during tensile test for 10 cycles at different peak stresses of (a) $40 \mathrm{MPa}$, (b) $70 \mathrm{MPa}$ and (c) $100 \mathrm{MPa}$. 

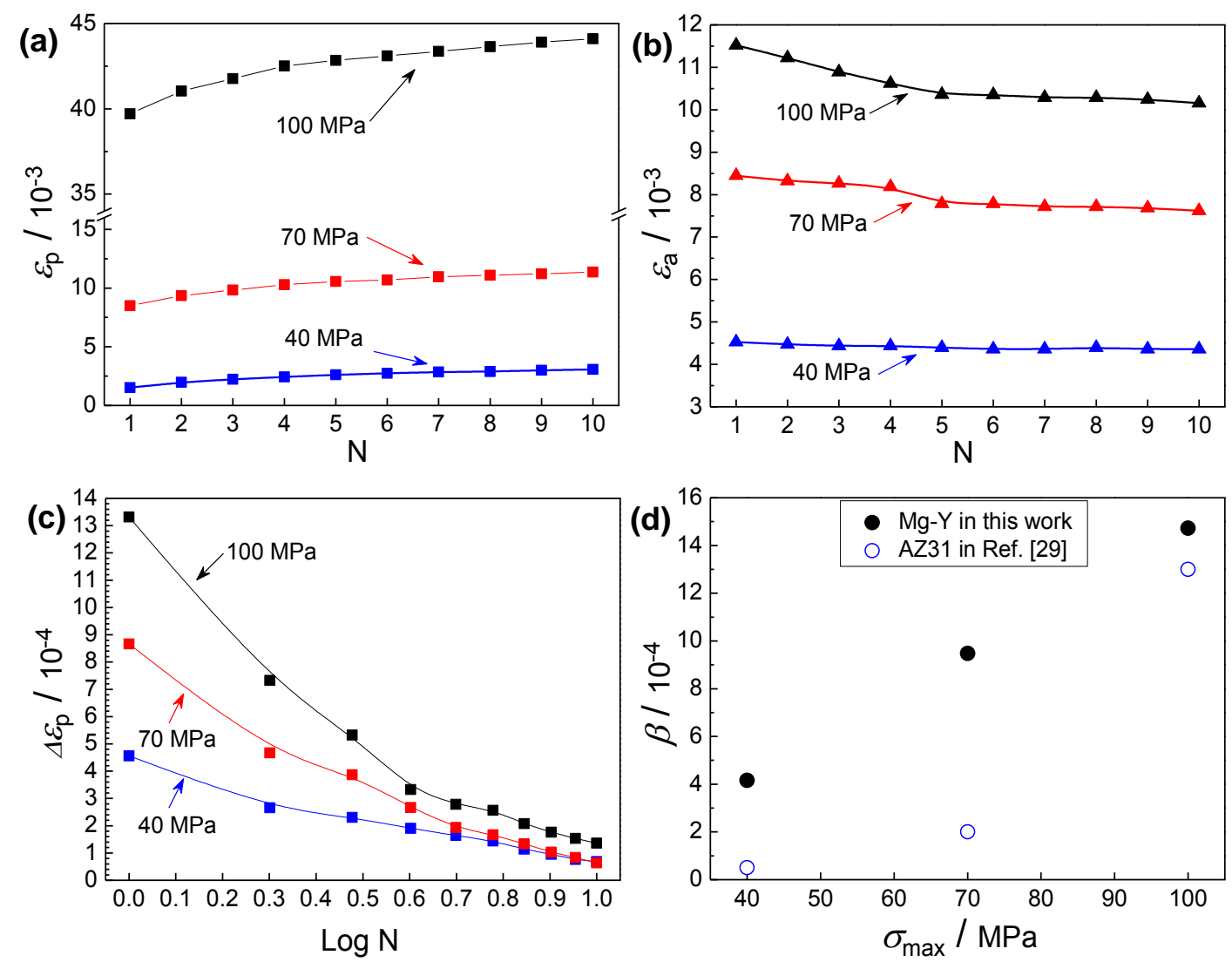

Fig. 4. Relationship between the cycle number $N$ and (a) plastic strain $\varepsilon_{\mathrm{p}}$, (b) anelastic strain $\varepsilon_{\mathrm{a}}$, and (c) plastic strain increment $\Delta \varepsilon_{\mathrm{p}}$, and (d) relationship between hardening constant $\beta$ and peak stress $\sigma_{\max }$. 

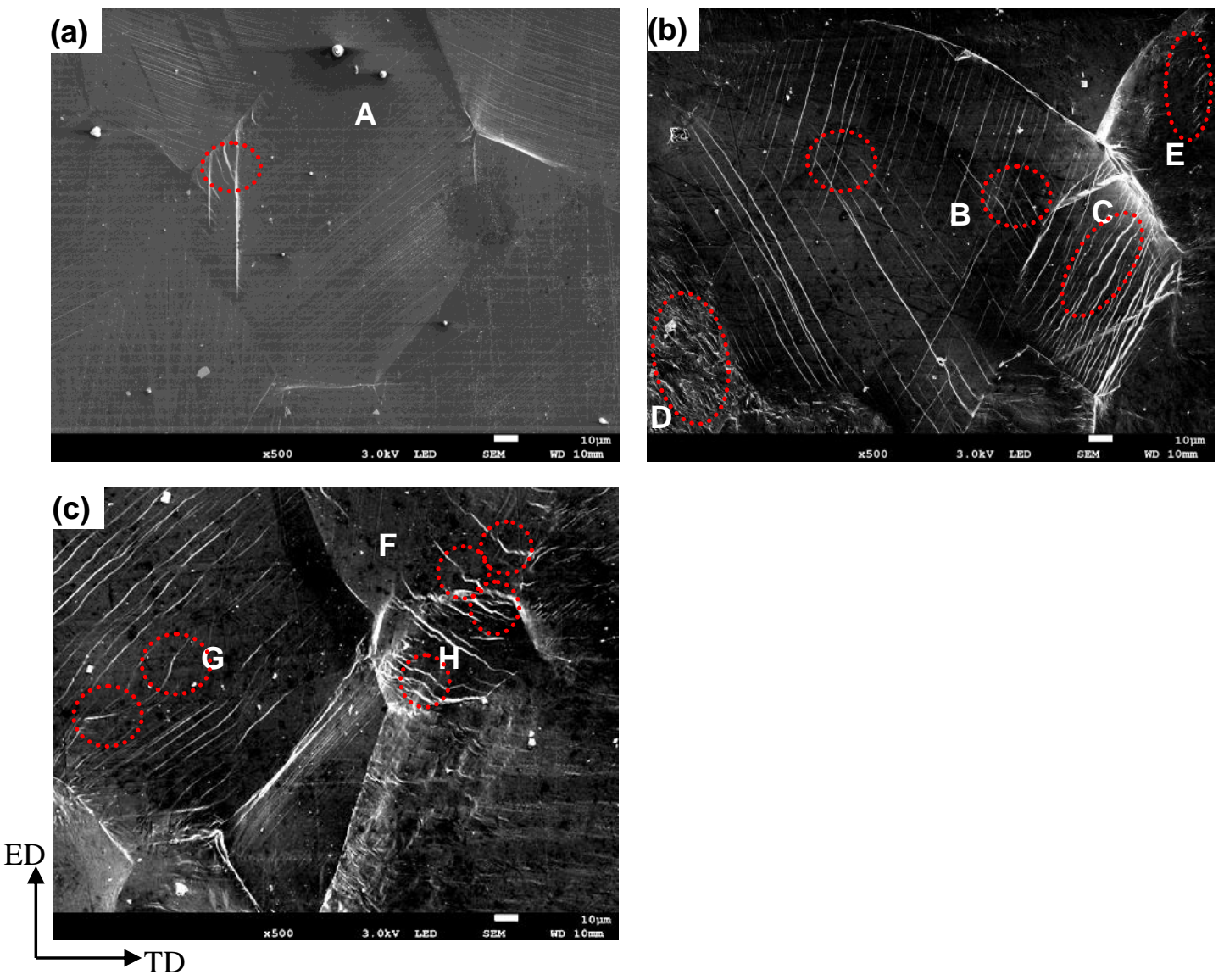

Fig. 5. SEM images of typical areas after tensile test for 10 cycles at the peak stress of (a) $40 \mathrm{MPa}$, (b) $70 \mathrm{MPa}$, and (c) $100 \mathrm{MPa}$. 

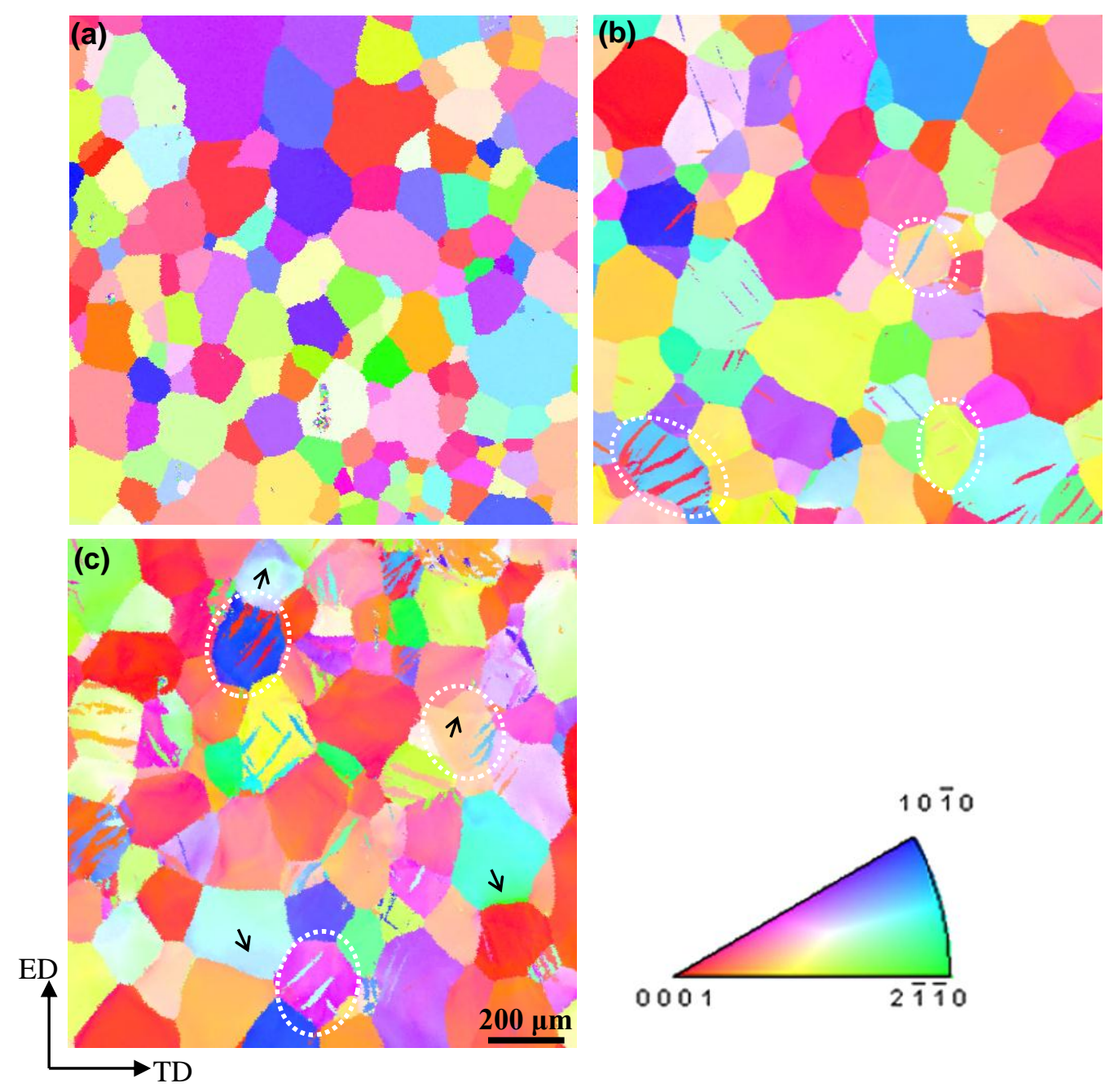

Fig. 6. Typical OIM maps of Mg-Y alloy after tensile test for 10 cycles at the peak stress of (a) 40 $\mathrm{MPa}$, (b) $70 \mathrm{MPa}$, and (c) $100 \mathrm{MPa}$. 


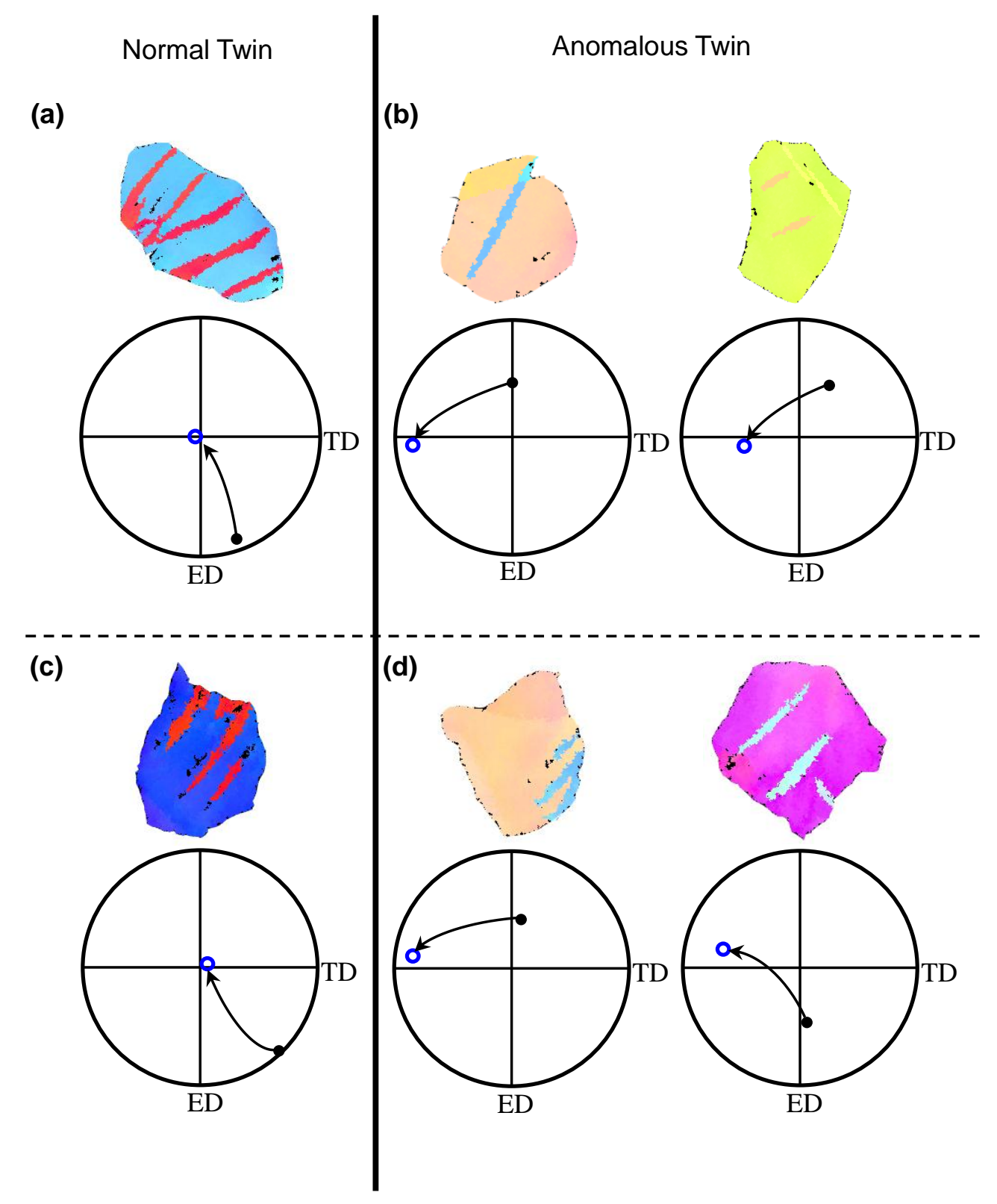

Fig. 7. Crystallographic orientations and $\{0001\}$ pole figures of the selected grains in Fig. 7: (a) normal twins at $\sigma_{\max }=70 \mathrm{MPa}$, (b) anomalous twins at $\sigma_{\max }=70 \mathrm{MPa}$, (c) normal twins at $\sigma_{\max }=100 \mathrm{MPa}$, and (d) anomalous twins at $\sigma_{\max }=100 \mathrm{MPa}$. 
Table 1

CRSS values for different deformation modes in Mg-Y, pure Mg and AZ31 alloy single crystals [52-54].

\begin{tabular}{cccccc}
\hline Mode & \multicolumn{5}{c}{ CRSS / MPa } \\
\cline { 2 - 6 } & Mg-0.5at\%Y & Mg-0.8at\%Y & Mg-1.0at\%Y & Pure Mg & AZ31 \\
\hline Basal & - & - & $10[53]$ & $1[53]$ & $2[54]$ \\
Prismatic & $12.8[52]$ & $22[52]$ & - & $8[52]$ & $60[54]$ \\
Pyramidal & - & - & - & - & $50[54]$ \\
$\{10 \overline{1} 2\}$ & $15[52]$ & $31[52]$ & - & $3.4[52]$ & $20[54]$ \\
\hline
\end{tabular}

